\title{
The subatlantic triangle: gateway to early localization of the atlantoaxial vertebral artery
}

\author{
Ali Tayebi Meybodi, MD, Sirin Gandhi, MD, Mark C. Preul, MD, and Michael T. Lawton, MD \\ Department of Neurological Surgery, Barrow Neurological Institute, Phoenix, Arizona
}

OBJECTIVE Exposure of the vertebral artery (VA) between C-1 and C-2 vertebrae (atlantoaxial VA) may be necessary in a variety of pathologies of the craniovertebral junction. Current methods to expose this segment of the VA entail sharp dissection of muscles close to the internal jugular vein and the spinal accessory nerve. The present study assesses the technique of exposing the atlantoaxial VA through a newly defined muscular triangle at the craniovertebral junction.

METHODS Five cadaveric heads were prepared for surgical simulation in prone position, turned $30^{\circ}-45^{\circ}$ toward the side of exposure. The atlantoaxial VA was exposed through the subatlantic triangle after reflecting the sternocleidomastoid and splenius capitis muscles inferiorly. The subatlantic triangle was formed by 3 groups of muscles: 1) the levator scapulae and splenius cervicis muscles inferiorly and laterally, 2) the longissimus capitis muscle inferiorly and medially, and 3) the inferior oblique capitis superiorly. The lengths of the VA exposed through the triangle before and after unroofing the C-2 transverse foramen were measured.

RESULTS The subatlantic triangle consistently provided access to the whole length of atlantoaxial VA. The average length of the VA exposed via the subatlantic triangle was $19.5 \mathrm{~mm}$. This average increased to $31.5 \mathrm{~mm}$ after the VA was released at the $\mathrm{C}-2$ transverse foramen.

CONCLUSIONS The subatlantic triangle provides a simple and straightforward pathway to expose the atlantoaxial VA. The proposed method may be useful during posterior approaches to the craniovertebral junction should early exposure and control of the atlantoaxial VA become necessary.

https://thejns.org/doi/abs/10.3171/2017.11.SPINE171068

KEYWORDS suboccipital triangle; dissecting aneurysm; far-lateral approach; extreme lateral infrajugular transcondylar approach; cerebral revascularization; surgical technique

$\mathrm{D}$ ESPITE various surgical approaches designed to access its different segments, surgical exposure of the extracranial vertebral artery (VA) is challenging. Embedded in a rich venous plexus, as the VA ascends through the transverse foramina of the cervical vertebrae, it is progressively protected by multiple layers of muscles. This anatomical complexity reaches its zenith at the craniocervical junction (occiput-C2 region), where the meandering course of the VA through the $\mathrm{C}-1$ and $\mathrm{C}-2$ foramina is covered by multiple intersecting muscles. ${ }^{30}$

Exposure of the upper extracranial segment of the VA between C-1 and C-2 (atlantoaxial VA) may become necessary during surgical treatment of a variety of pathologies including neoplastic, vascular, congenital, and degenerative lesions., ${ }^{3,1726}$ Such an exposure may also be needed for reconstructive procedures on the VA, including those involving a bypass between the external carotid artery (ECA) and the VA., $, 10,15,27$ This is usually achieved using lateral approaches through the anterior triangle of the neck ${ }^{4,7,12,14,20,21,29,32,45,46}$ or through an inferior extension of the far-lateral approach; $;, 30,44$ however, these approaches require early identification of the $\mathrm{C}-1$ transverse process and detachment of the deep muscles of the craniovertebral junction in close vicinity of the VA., ${ }^{1,414,29,46}$ Such detachment usually entails sharp dissection maneuvers that might cause VA injury. Furthermore, when the C-1 transverse process is not available as a landmark (e.g., due to tumor invasion), no other clear landmark exists to efficiently control the atlantoaxial VA.

We performed cadaveric surgical explorations to find

ABBREVIATIONS ECA = external carotid artery; IJV = internal jugular vein; $\mathrm{SCM}=$ sternocleidomastoid muscle; VA = vertebral artery. SUBMITTED September 29, 2017. ACCEPTED November 7, 2017.

INCLUDE WHEN CITING Published online April 27, 2018; DOI: 10.3171/2017.11.SPINE171068. 
an anatomical gateway to expose the atlantoaxial VA through a posterior craniovertebral approach. We identified an anatomical triangle at the craniovertebral junction, the subatlantic triangle, the exposure of which leads to early and efficient localization of the atlantoaxial VA. This study defines the boundaries and contents of this triangle and the surgical steps to expose it.

\section{Methods}

Five cadaveric heads, embalmed in an alcohol-based customized solution, were injected with colored silicone and prepared for surgical simulation. Of the 5 specimens, 4 were Caucasian female specimens and 1 was a Caucasian male specimen (mean age 69.7 years, range 37-88 years). None of the specimens had any known intracranial or craniocervical junction pathology. A preliminary dissection was performed on 1 craniovertebral junction to assess the anatomical location of the atlantoaxial segment of the VA and its relationship with the adjacent anatomical structures. Based on the findings of this preliminary dissection, the remaining heads (a total of 9 sides) underwent surgical simulations to expose the atlantoaxial VA through the subatlantic triangle as follows.

\section{Exposure of the Subatlantic Triangle}

Each head was placed in a 3-pin Mayfield clamp in a prone position, with the vertex flexed toward the floor and turned $30^{\circ}-45^{\circ}$ toward the side of dissection, such that the mastoid process was the highest point in the field. This would mimic the positioning for a far-lateral approach. An L-shaped skin incision was started at the anterior border of the sternocleidomastoid muscle (SCM), $5 \mathrm{~cm}$ below the mastoid tip, and extended superiorly along the anterior SCM border to the level of the external auditory meatus, and then turned medially to reach the inion. The skin flap was reflected inferiorly and medially to expose the SCM (Fig. 1A). Leaving a 5-mm cuff, the SCM was sharply detached from its insertion to the mastoid process to expose the underlying splenius capitis muscle (Fig. 1B), which was similarly detached from its insertion to the superior nuchal line. This maneuver exposed the underlying semispinalis capitis medially, and longissimus capitis laterally (Fig. 1C). The fat pad lying lateral to the longissimus capitis was then removed to expose the levator scapulae and splenius cervicis muscles (Fig. 1D). These muscles attached to the posterior aspect of the C-1 and C-2 transverse processes, which were palpable in the surgical field. The subatlantic triangle was then identified between 3 groups of muscles: 1) the levator scapulae and splenius cervicis muscles inferiorly and laterally, 2) the longissimus capitis muscle inferiorly and medially, and 3) the inferior oblique capitis superiorly. Next, the atlantoaxial VA was found inside the subatlantic triangle (Figs. 1D and 2). The important anatomical relationships within and in the vicinity of the subatlantic triangle were observed. Also, the length of the VA exposed within the triangle was measured before and after unroofing the $\mathrm{C}-2$ transverse foramen.

\section{Results}

The atlantoaxial VA was successfully exposed through the subatlantic triangle in all specimens. The VA was surrounded by a venous plexus, and the anterior ramus of the C-2 nerve crossed the posterior aspect of the VA in all specimens (Figs. 2 and 3). The average length of the exposed VA was $19.5 \pm 3.1 \mathrm{~mm}$ (range $17-25 \mathrm{~mm}$ ) before and $31.5 \pm 2.6 \mathrm{~mm}$ (range $28-35 \mathrm{~mm}$ ) after unroofing the $\mathrm{C}-2$ transverse foramen. The transverse processes of C-1 and C-2 were always palpable within the boundaries of the subatlantic triangle. The anterior ramus of the $\mathrm{C}-2$ spinal nerve crossed the posterior aspect of the atlantoaxial VA in all specimens. The posterior ramus of the C-2 nerve could also be found in the medial wall of the triangle coursing posteriorly (Figs. 2 and 3); however, the spinal accessory nerve did not cross the triangle in any of the specimens. When dissection was continued anterior to the levator scapulae muscle (i.e., anterolateral to the subatlantic triangle), the spinal accessory nerve was found to emerge under the posterior belly of the digastric, coursing inferiorly between the internal jugular vein (IJV) and the levator scapulae to reach the undersurface of the SCM (Fig. 4). The levator scapulae and splenius cervicis muscles formed a muscular cushion between the atlantoaxial VA and the IJV in all specimens (Fig. 4).

Other structures consistently found within the subatlantic triangle included the $\mathrm{C}-2$ pars interarticularis abutting the anteromedial aspect of the atlantoaxial VA and the $\mathrm{C} 2-3$ facet joint located at the inferior half of the triangle (Figs. 2 and 4).

\section{Discussion}

Utilization of the subatlantic triangle consistently leads to exposure of the whole length of the atlantoaxial VA (Fig. 5). Our results show that the subatlantic triangle is an efficient corridor to gain control over the atlantoaxial VA with minimal use of sharp dissection and without exposing adjacent critical neurovascular structures, including the IJV and the spinal accessory nerve.

\section{Indications and Current Existing Approaches for Exposure of the Atlantoaxial VA}

In 1830, Louis Joseph Sanson reported the first surgical exposure of a gunshot-induced aneurysm of the atlantoaxial VA. ${ }^{31}$ He wrote, "The vertebral artery cannot be ligated...nor compressed...The wounds of this vessel are beyond the resources of art." More than 180 years later, although much more confident, the cerebrovascular surgeon may still hesitate to surgically access the atlantoaxial VA, as evidenced by the increasing number of endovascular procedures to treat the dissecting aneurysms of this artery. 6,24,33,34 However, surgical exposure of the atlantoaxial VA may be necessary in a variety of craniovertebral junction pathologies, including traumatic, neoplastic, vascular, congenital, and degenerative lesions. ${ }^{1,2,9,10,12,14,21,27,43}$ Dissecting aneurysms or tumors involving the $V_{3}$ VA clearly exemplify scenarios in which vascular control on the atlantoaxial VA becomes necessary when a surgical treatment is contemplated. Another example is degenerative joint disease, which causes impingement of the atlantoaxial VA and requires direct decompression (e.g., bow hunter's syndrome). ${ }^{16,18,19,25,28}$ 

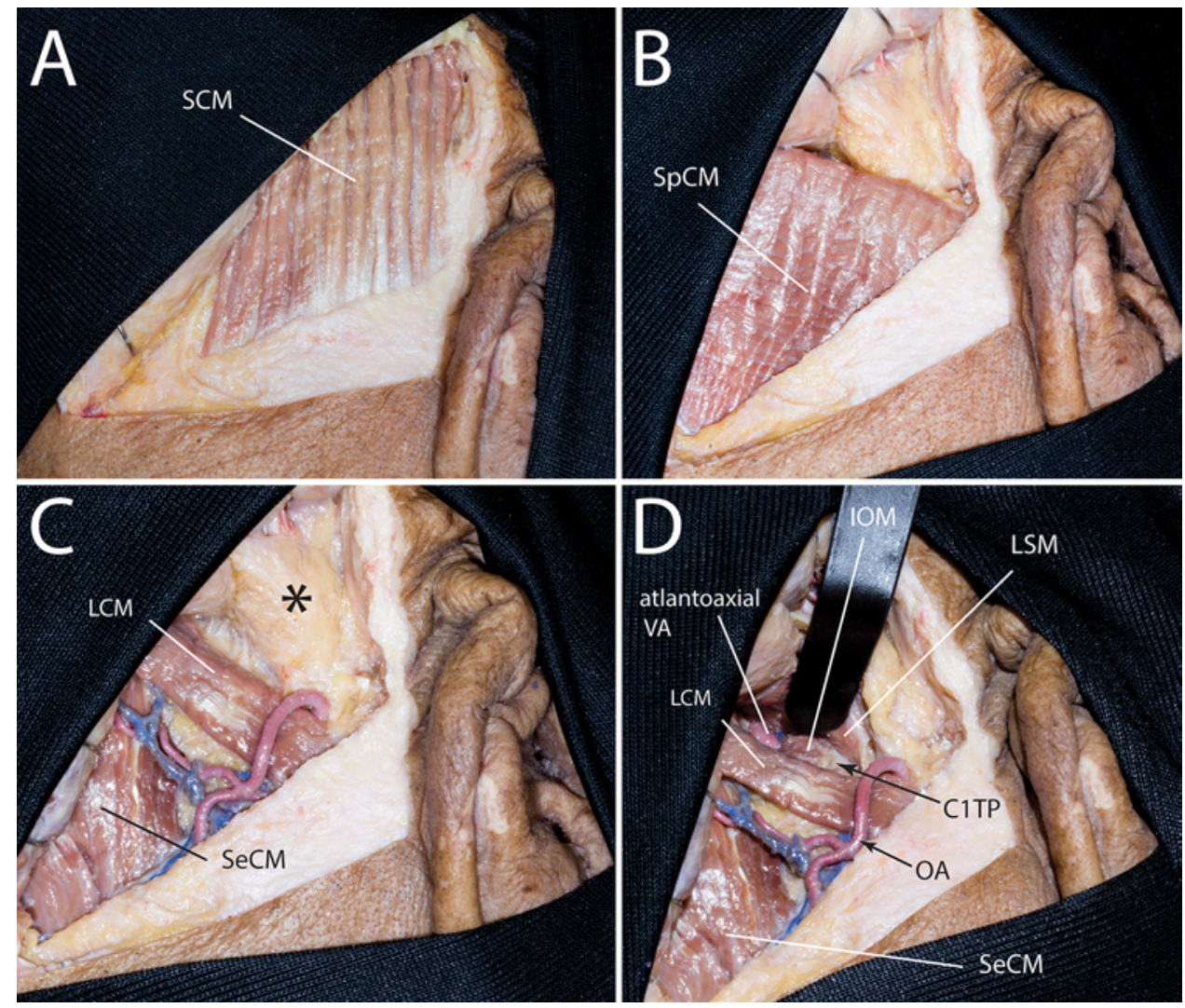

FIG. 1. Stepwise surgical simulation to expose the left atlantoaxial VA through the subatlantic triangle. A: After positioning the head for a far-lateral approach, an L-shaped skin incision is started $5 \mathrm{~cm}$ below the mastoid tip at the anterior border of the sternocleidomastoid muscle. Reflection of the skin flap exposes the sternocleidomastoid muscle. B: The sternocleidomastoid is detached from its insertion and reflected inferomedially to expose the underlying splenius capitis muscle. C: Similarly, the splenius capitis muscle is detached to expose the semispinalis capitis, medially, and the longissimus capitis, laterally. Note the fat pad lying lateral to the longissimus muscle, which covers the underlying subatlantic triangle (asterisk). D: Following removal of the fat pad lateral to the longissimus muscle, the subatlantic triangle is exposed with the atlantoaxial VA. The subatlantic triangle is limited by the inferior oblique capitis muscle superiorly, the levator scapulae muscle inferolaterally, and the longissimus capitis muscle inferomedially. C1TP = C-1 transverse process; $I O M=$ inferior oblique muscle; $L C M=$ longissimus capitis muscle; $L S M=$ levator scapulae muscle; OA = occipital artery; $\mathrm{SeCM}=$ semispinalis capitis muscle; $\mathrm{SpCM}=$ splenius capitis muscle. Figure is available in color online only.

The lateral approaches to this segment of the VA are well known. In these approaches, the plane between the SCM and the IJV is developed while the spinal accessory nerve is dissected all the way up to the skull base to enable its retraction away from the field. $4,12,14,15,20,21,46 \mathrm{Next}$, the C-1 transverse process is identified by palpation (Fig. 6)..$^{29,46}$ Finally, the levator scapulae and splenius cervicis muscles are detached from the $\mathrm{C}-1$ transverse process to expose the VA (Fig. 6B). This approach is usually performed with the patient in a supine position, with the head turned contralaterally, or in the lateral position. ${ }^{14,15,29,46}$ Therefore, this approach is ideal for an ECA-VA bypass, ${ }^{10,15,27}$ as the carotid sheath and the VA are both exposed during the same surgical exposure.

When addressing the pathology necessitates a prone position, exposure of the atlantoaxial VA is difficult with a lateral approach, because it requires dissection between the SCM and the IJV. Classically, when a posterior trajectory is considered (e.g., to address a posterior fossa or posterior craniovertebral junction pathology), a far-lateral approach can be used to access the suboccipital $\left(\mathrm{V}_{3}\right)$ and atlantoaxial segments of the VA..$^{30,42}$ This is usually performed with subperiosteal dissection of the muscles of the craniovertebral junction down to the C-2 vertebra. The main disadvantage of this technique is that the risk of VA injury increases as the exposure is extended further inferiorly and laterally during the far-lateral approach. ${ }^{30}$ This risk is increased because when the bulk of muscles is being stripped off the C-1 and C-2 laminae, no other landmark exists to localize the atlantoaxial VA except the transverse processes of the C-1 and C-2. Also, bleeding from muscle and bone during the subperiosteal dissection can further obscure the anatomy and increase the risk of vessel injury. Compounded by the tortuous course of the atlantoaxial VA, such a scenario could easily lead to iatrogenic VA injury. Therefore, early and bloodless localization of the atlantoaxial VA during the procedure could greatly increase safety and efficiency.

\section{Advantages of Exposing the VA via the Subatlantic Triangle}

The subatlantic triangle can be exposed in the initial steps of the muscular stage of the far lateral approach (Fig. 


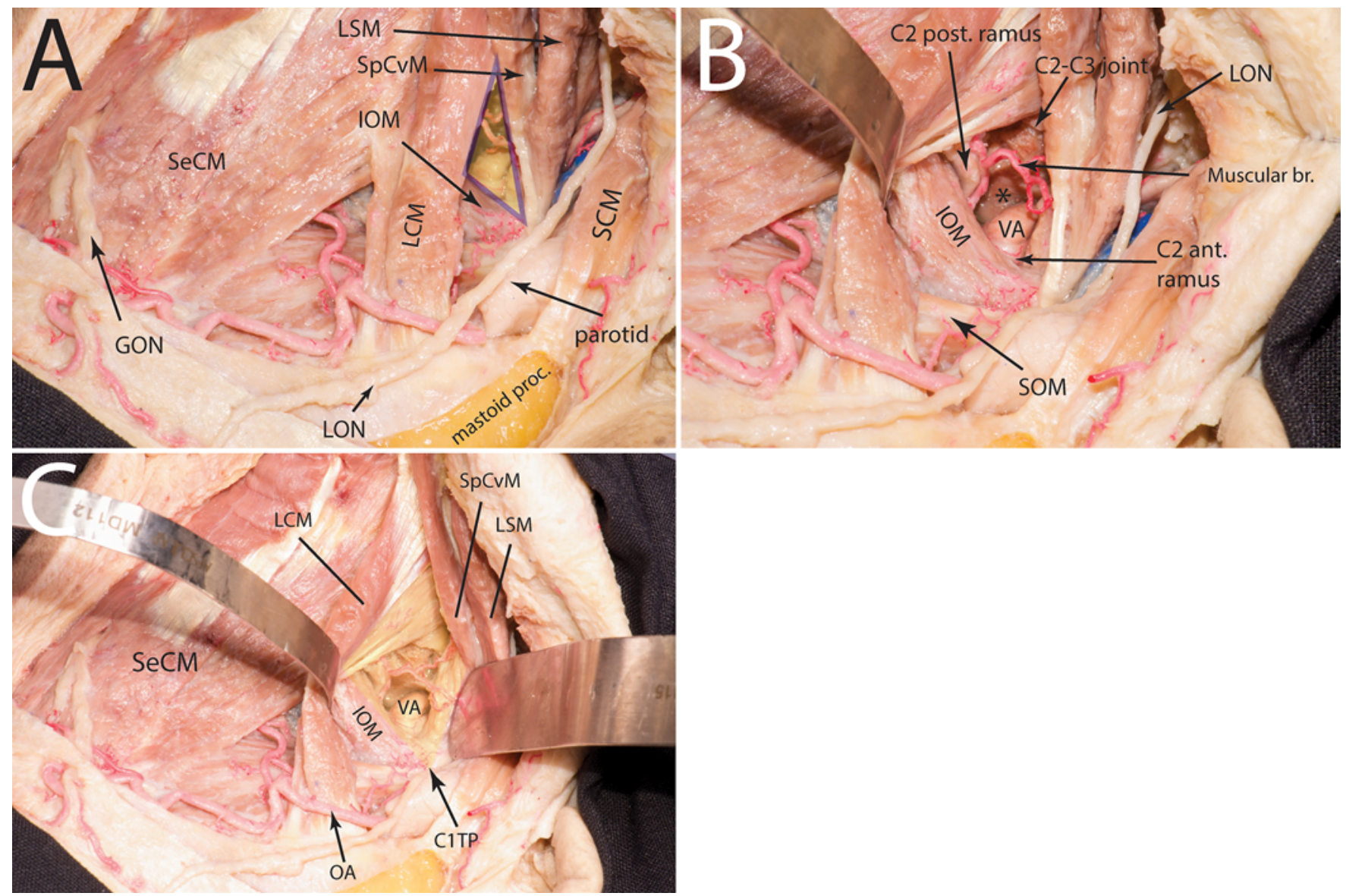

FIG. 2. Dissection of the left craniovertebral junction to show the boundaries and contents of the subatlantic triangle. A: The subatlantic triangle (purple) is formed anterolateral to the longissimus capitis muscle. It is formed between 3 groups of muscles: 1) the levator scapulae and splenius cervicis muscles inferiorly and laterally, 2) the longissimus capitis muscle inferiorly and medially, and 3) the inferior oblique capitis superiorly. B: The longissimus capitis muscle has been retracted medially to widen the triangle. Please note the C-2 pars interarticularis (asterisk) and the C2-3 facet joint exposed within the triangle. The C-2 ganglion is not located in the subatlantic triangle. However, the posterior and anterior rami of the $\mathrm{C}$-2 spinal nerve are inside the triangle. The anterior $\mathrm{C}-2$ ramus crosses the posterior aspect of the atlantoaxial VA. The vertebral artery may have muscular and/or radicular branches originating at this segment. C: Retracting the levator scapulae and the splenius cervicis muscles widens the subatlantic triangle (highlighted). Note: The lesser occipital nerve has been dissected and saved during dissection. $\mathrm{Br} .=$ branch; C1TP $=\mathrm{C}-1$ transverse process; $\mathrm{C} 2$ ant. ramus $=\mathrm{C}-2$ anterior ramus; $\mathrm{C} 2$ post. ramus $=\mathrm{C}-2$ posterior ramus; $\mathrm{GON}=$ greater occipital nerve; $\mathrm{IOM}=$ inferior oblique muscle; $\mathrm{LCM}=$ longissimus capitis muscle; $\mathrm{LON}=$ lesser occipital nerve; $\mathrm{LSM}=$ levator scapulae muscle; $\mathrm{OA}=$ occipital artery; Proc. $=$ process; $\mathrm{SeCM}=$ semispinalis capitis muscle; $\mathrm{SpCvM}=$ splenius cervicis muscle. Figure is available in color online only.

1). This triangle provides a simple straightforward path to efficiently expose and control the atlantoaxial VA and offers several advantages over the existing anterolateral and posterior approaches to expose the atlantoaxial VA. First, this triangle uses a natural corridor (between the longissimus capitis and levator scapulae muscles) to target the atlantoaxial VA without the need to detach the deep muscular layers of the neck. This feature adds to the technical safety of this method, as no sharp dissection is needed to detach the muscles attached to the $\mathrm{C}-1$ transverse process, which is a routine maneuver proposed in currently existing lateral approaches. . $^{1,414,29,46}$ Such sharp dissection would endanger adjacent vascular structures, including the VA and the IJV. Using the subatlantic triangle, once the superficial muscles (SCM and splenius capitis) are detached from the superior nuchal line, no additional sharp muscle dissection is necessary to expose the atlantoaxial VA. Even detachment of the splenius capitis may not be necessary if this muscle does not overlap with the lateral edge of the underlying longissimus capitis (Fig. 4). Second, in all lateral approaches, the atlantoaxial VA is accessed through development of a plane tangential to the posterior aspect of the IJV., $, 5,14,27,41$ Such technique inherently puts the IJV at risk, without any protective measure. Furthermore, approaching the atlantoaxial segment of the VA via this plane requires exposure and transposition of the spinal accessory nerve that normally crosses the surgical field (Fig. 5). ${ }^{4,14,27,41}$ In contrast, access to the VA via the subatlantic triangle may minimize the risk of IJV injury because the IJV is not exposed during this approach (Fig. 1). Also, a cushion formed by the levator scapulae and splenius cervicis muscles is kept between the VA and 


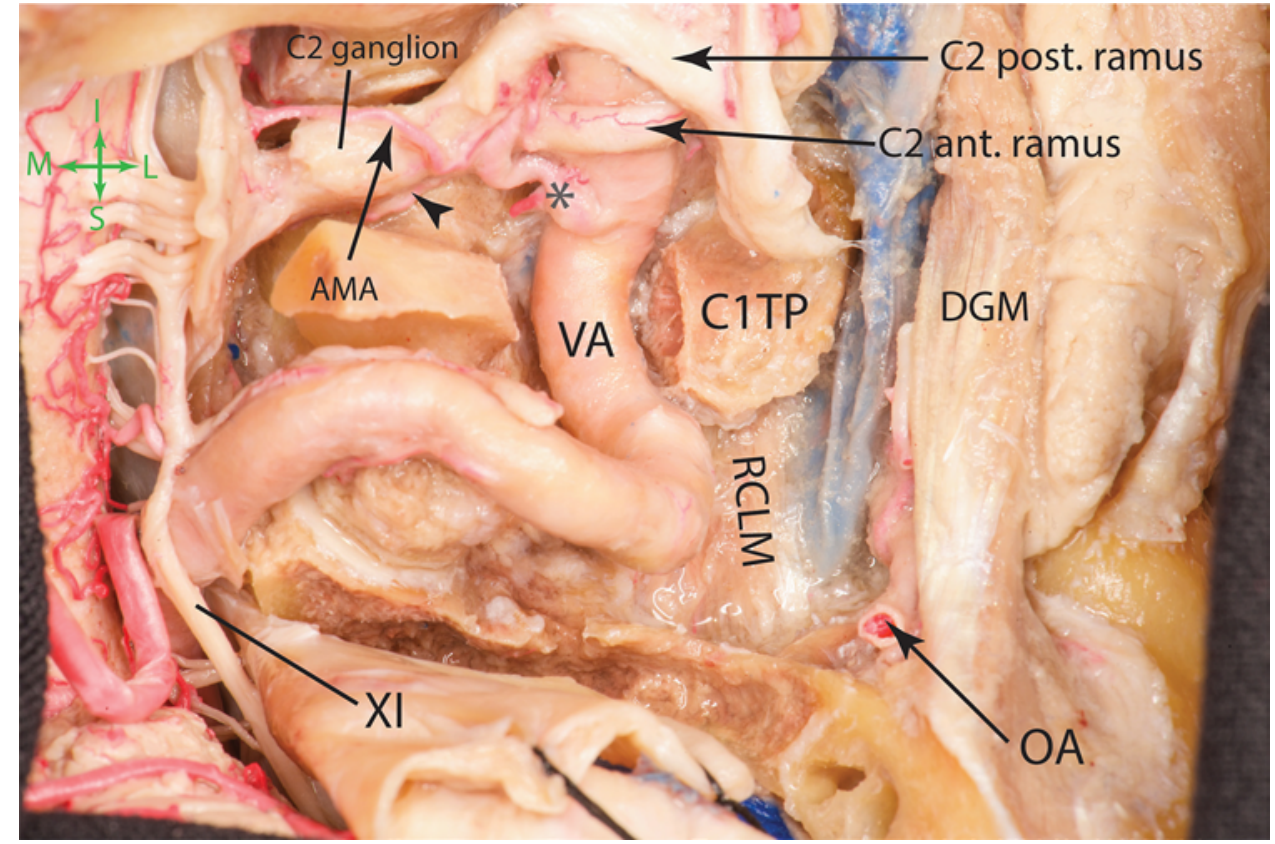

FIG. 3. Dissection of the left craniovertebral junction and exposure of the course of the atlantoaxial and suboccipital segments of the VA. The $\mathrm{C}-2$ ganglion is located just posterior to the $\mathrm{C} 2-3$ facet joint. Moving laterally the $\mathrm{C}-2$ nerve divides into the anterior and posterior rami. The posterior ramus turns posteriorly while the anterior ramus embraces the atlantoaxial VA. The atlantoaxial VA may have a muscular (asterisk) and/or radicular branch (arrowhead) at this level. It may also give rise to the anterior meningeal artery which supplies the anterior dura of the craniovertebral junction. Note that the cranial aspect of the specimen is at the bottom of the figure -consult the green compass). AMA = anterior meningeal artery; $\mathrm{C} 1 \mathrm{TP}=\mathrm{C}-1$ transverse process; $\mathrm{C} 2$ ant. ramus $=\mathrm{C}-2$ anterior ramus; $\mathrm{C} 2$ post. ramus $=\mathrm{C}-2$ posterior ramus; $\mathrm{DGM}=$ digastric muscle; $\mathrm{I}=$ inferior; $\mathrm{L}=$ lateral; $\mathrm{M}=$ medial; $\mathrm{OA}=$ occipital artery; $\mathrm{RCLM}=$ rectus capitis lateralis muscle; $\mathrm{S}$ = superior; $\mathrm{XI}=$ accessory nerve. Figure is available in color online only.

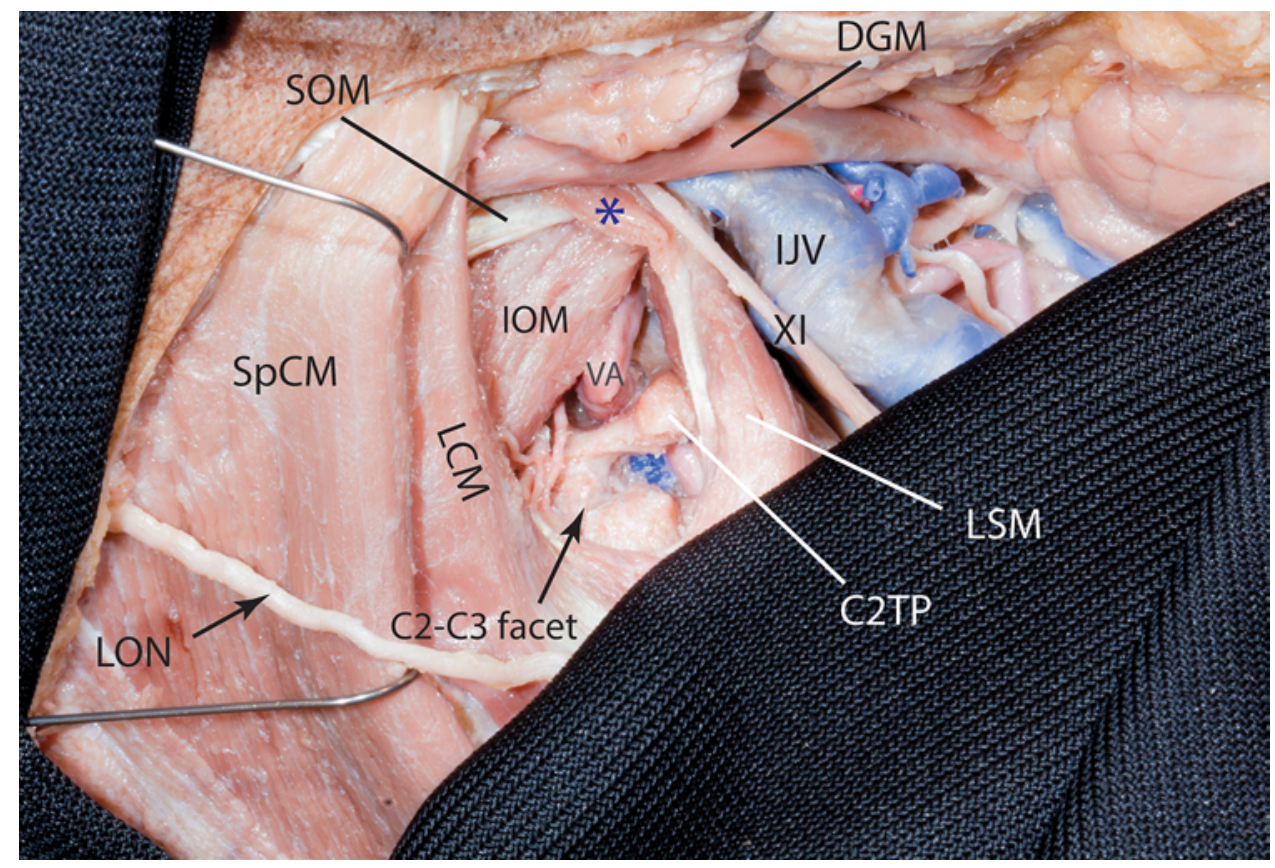

FIG. 4. Posterolateral dissection of the right side of a cadaveric neck showing the exposure of the atlantoaxial VA and adjacent structures within the subatlantic triangle. Please note that the accessory nerve does not cross the subatlantic triangle and is related to the anterior aspect of the levator scapulae muscle. Also, the subatlantic triangle exposes the VA without the need to expose the internal jugular vein. A muscular cushion formed by the levator scapulae and splenius cervicis muscles separates the internal jugular vein and the atlantoaxial VA. The blue asterisk marks the rectus capitis lateralis muscle. C2TP = C-2 transverse process; $\mathrm{DGM}=$ digastric muscle; $\mathrm{IOM}=$ inferior oblique muscle; $\mathrm{LCM}=$ longissimus capitis muscle; $\mathrm{LON}=$ lesser occipital nerve; $\mathrm{LSM}=$ levator scapulae muscle; $\mathrm{SOM}=$ superior oblique muscle; $\mathrm{SpCM}=$ splenius capitis muscle; $\mathrm{XI}=$ accessory nerve. Figure is available in color online only. 


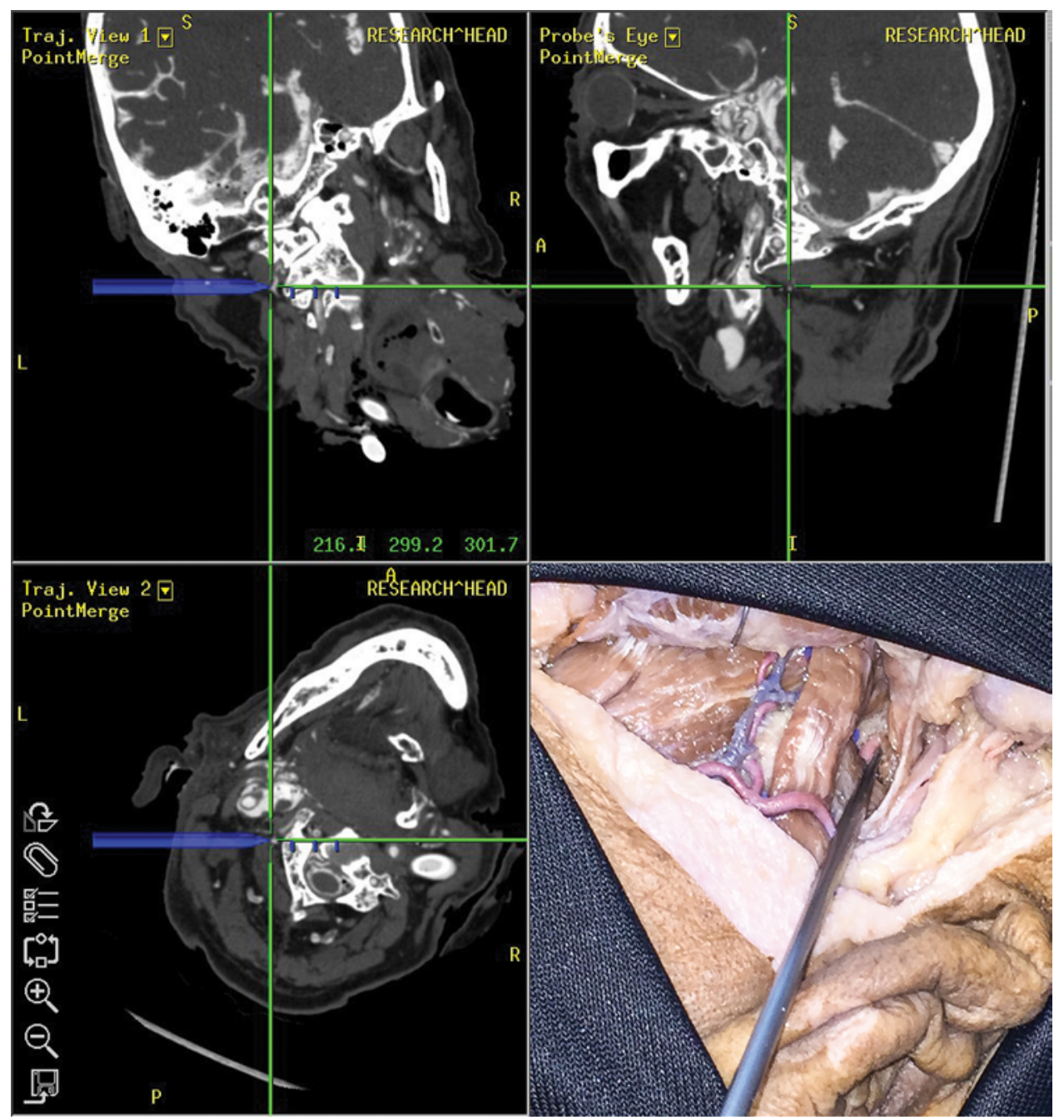

FIG. 5. Neuronavigation system used to demonstrate and verify the exposure of the atlantoaxial VA via the subatlantic triangle. The right inferior panel shows the navigation pointer pointing at the atlantoaxial vertebral artery. Figure is available in color online only.

the IJV. In addition, the accessory nerve is not encountered when the subatlantic triangle is used.

Other adjacent nerves (such as the mandibular branch of the facial nerve, the vagus and hypoglossal nerves, and the sympathetic trunk) may also be exposed and injured during VA exposure through the anterior triangle of the neck (Fig. 5). ${ }^{23,42}$ Such neural injuries are assumed to be uncommon with our proposed approach, because exposure of the subatlantic triangle does not expose any of these nerves. The only neural structure encountered when accessing the VA through the subatlantic triangle was the anterior ramus of the C-2 nerve (Figs. 2 and 3). This branch is the natural companion of the VA between the $\mathrm{C}-1$ and $\mathrm{C}-2$ vertebrae and most frequently crosses the posterior aspect of the artery. ${ }^{10,46}$ In all approaches, this nerve should be cut to expose the VA. Severing the C-2 nerve is not generally reported to cause complications $;^{15}$ however, some have associated it with postoperative headaches. ${ }^{11}$ It is possible to pass the stumps of the nerve underneath the VA and perform a reanastomosis as suggested by Yang et al. ${ }^{46}$
Another advantage of the use of the subatlantic triangle is that even without unroofing the C-2 transverse foramen, it could expose greater lengths of the atlantoaxial VA (approximately $20 \mathrm{~mm}$ ) compared with the lateral approaches (approximately $15 \mathrm{~mm}) .{ }^{15}$ This length even increases by $>$ $50 \%$ when unroofing of the C-2 transverse foramen, which shows a promising potential of the proposed approach to generously expose the VA. Exposing such a long segment of the VA (up to $30 \mathrm{~mm}$ ) may greatly facilitate bypass procedures by providing adequate space for placing temporary clips and performing an anastomosis. Also, when an ECA-VA bypass is planned during a posterior approach to address the pathology, the ECA can be efficiently exposed through the posterior triangle of the neck as previously described (Fig. 7). ${ }^{39}$

Another clear advantage of the proposed approach is evident when an extradurally originating posterior inferior cerebellar artery arising from the atlantoaxial VA needs to be exposed. ${ }^{13,35,36,38}$ In such cases, the simple and straightforward nature of using the subatlantic triangle may add to surgical safety and efficiency. Table 1 compares the fea- 

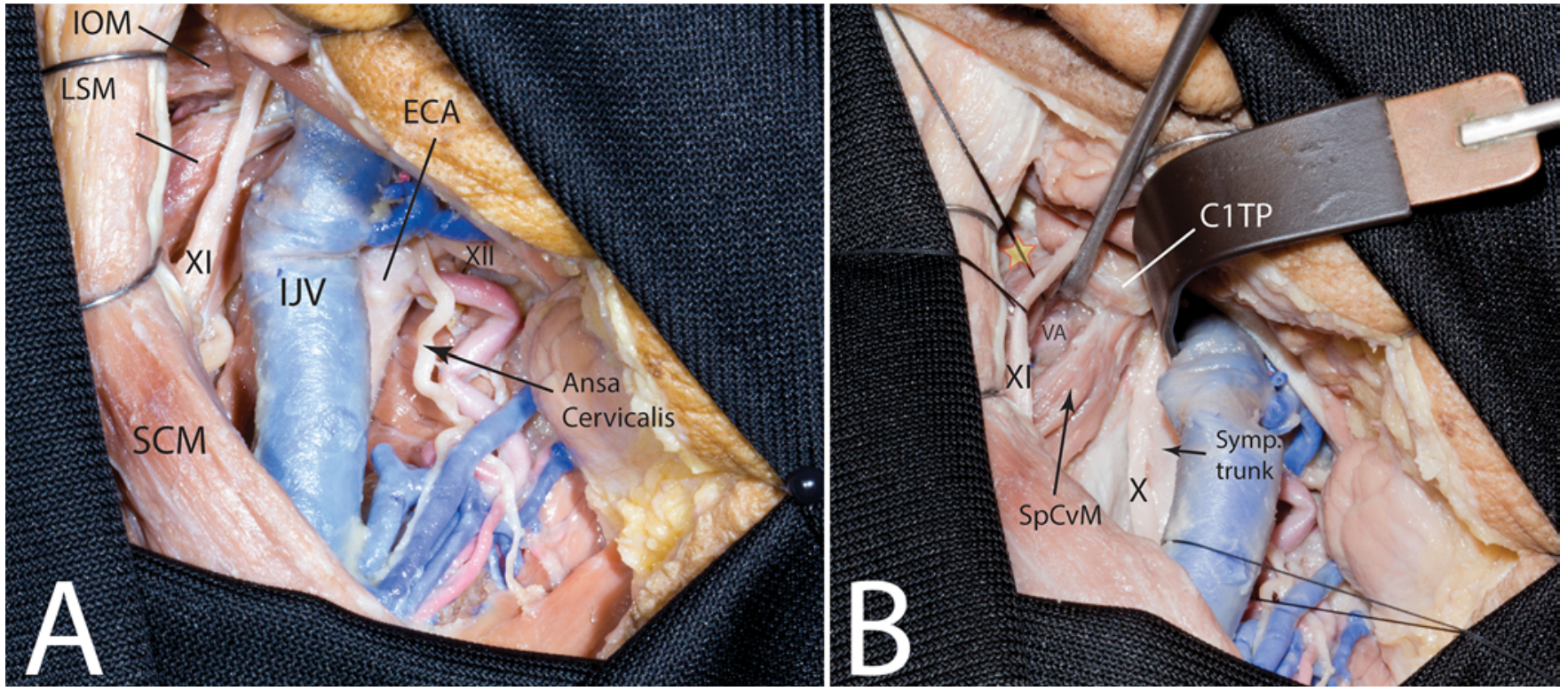

FIG. 6. Cadaveric surgical simulation showing the anterolateral approach to the atlantoaxial VA. A: The carotid sheath containing the internal jugular vein is exposed in the anterior triangle of the neck medial to the sternocleidomastoid muscle. The accessory nerve is exposed lateral to the internal jugular vein. The $\mathrm{C}-1$ transverse process is palpated at the superior point of exposure. B: The internal jugular vein is retracted medially and the accessory nerve is also retracted away from the surgical field. The plane between the sternocleidomastoid and the internal jugular vein is developed. This exposes the levator scapulae and splenius cervicis muscles attached to the posterior aspect of the C-1 transverse process. The atlantoaxial VA could be found medial (deep) to the levator scapulae (elevated and marked with a yellow star). The levator scapulae muscle is routinely detached from C-1 transverse process to widen the VA exposure (not shown). Note the proximity of the sympathetic trunk and the vagus nerve during exposure of the VA via a lateral approach. C1TP = C-1 transverse process; IJV = internal jugular vein; IOM = inferior oblique muscle; LSM = levator scapulae muscle; SCM = sternocleidomastoid muscle; SpCvM = splenius cervicis muscle; Symp. = sympathetic; $X=$ vagus nerve; $\mathrm{XI}=$ accessory nerve; $\mathrm{XII}=$ hypoglossal nerve. Figure is available in color online only.

tures of exposing the atlantoaxial VA though the subatlantic triangle versus alternative existing approaches.

Finally, wound closure could be performed in layers by approximating the detached superficial muscles. Even if more extensive exposures are required, the exposure of the subatlantic triangle would not hinder closure.

\section{Subatlantic Triangle Versus Suboccipital Triangle}

As the suboccipital triangle is commonly used for exposing the $\mathrm{V}_{3}$ segment of the VA, it is critical to delineate the surgical-anatomical differences between these two triangles. The suboccipital triangle is bounded by the rectus capitis posterior major, superior oblique, and inferior oblique muscles. ${ }^{30}$ This triangle (usually exposed via a farlateral approach) is used for the surgical exposure of the suboccipital $\left(\mathrm{V}_{3}\right)$ segment of the VA when the $\mathrm{V}_{3}$ segment is being considered as a donor or recipient for a bypass procedure. ${ }^{37,46}$ In contrast, the subatlantic triangle is located inferolateral to the suboccipital triangle (i.e., inferior and lateral to C-1 and inferior oblique muscle). Surgical exploration of this triangle leads us to the most superior portion of the $\mathrm{V}_{2}$ VA (atlantoaxial VA), which could be used as a donor or recipient in various craniovertebral junction of posterior fossa pathologies (Table 1).

\section{Subatlantic Triangle Versus the Inferior Suboccipital Triangle}

Recently, La Rocca et al. described the inferior suboc- cipital triangle for early localization of the atlantoaxial VA. ${ }^{22}$ This triangle is bound by the following structures: 1 ) the inferior oblique capitis muscle, superiorly, 2) the posterior intertransverse muscle, laterally, and 3) C-2 lamina, inferiorly. However, their approach requires a medialto-lateral subperiosteal dissection of the craniovertebral

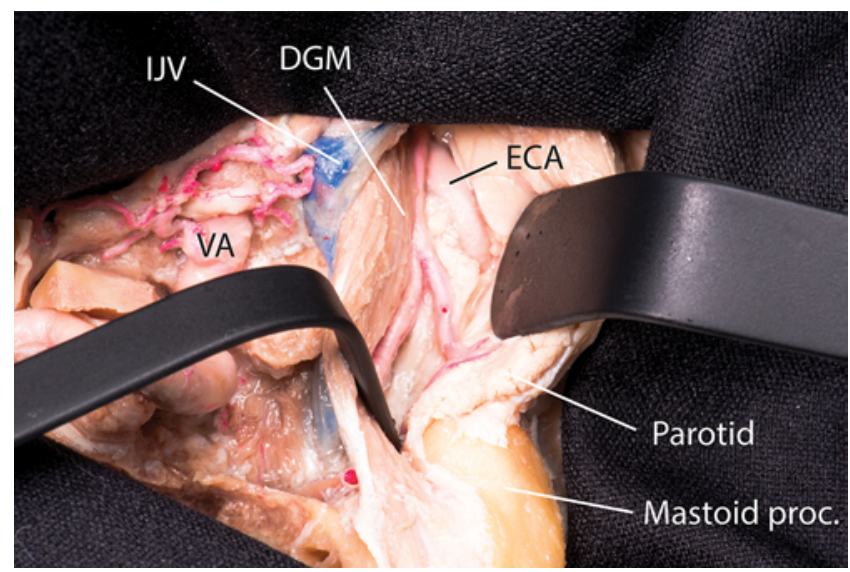

FIG. 7. Exposure of the ECA through the posterior triangle of the neck. The ECA is exposed through a plane developed between the parotid gland and the posterior belly of the digastric muscle. When the VA is exposed through the subatlantic triangle, a VA-ECA anastomosis can be completed by simultaneous exposure of the ECA in the operative field. Proc. $=$ process. Figure is available in color online only. 
TABLE 1. Comparison between the current practiced approaches and the subatlantic triangle approach to expose the atlantoaxial VA

\begin{tabular}{|c|c|c|c|c|c|}
\hline Approach* & Essentials of Technique & Advantages & Disadvantages & Sample Clinical Scenarios* & $\begin{array}{l}\text { Procedure } \\
\text { Examples* }\end{array}$ \\
\hline $\begin{array}{l}\text { Anterior/an- } \\
\text { terolateral } \\
\text { approaches }\end{array}$ & $\begin{array}{l}\text { Detachment of SCM } \\
\text { Dissection \& transposi- } \\
\text { tion of the spinal } \\
\text { accessory nerve } \\
\text { Developing the plane } \\
\text { posterior to IJV } \\
\text { Identification of C-1 } \\
\text { transverse process } \\
\text { Detaching levator scapu- } \\
\text { lae \& splenius cervicis } \\
\text { from C-1 transverse } \\
\text { process }\end{array}$ & $\begin{array}{l}\text { Compatible w/ lateral \& } \\
\text { supine positions } \\
\text { Gaining proximal control } \\
\text { relatively early during the } \\
\text { procedure }\end{array}$ & $\begin{array}{l}\text { Risk of IJV injury } \\
\text { Risk of spinal acces- } \\
\text { sory nerve injury } \\
\text { Need for sharp } \\
\text { muscle dissection } \\
\text { near the VA } \\
\text { High risk of VA injury } \\
\text { when C-1 trans- } \\
\text { verse process is } \\
\text { damaged or infil- } \\
\text { trated by tumor }\end{array}$ & $\begin{array}{l}\text { Vertebrobasilar insufficiency } \\
\text { C1-2 VA compression because } \\
\text { of degenerative joint disease }\end{array}$ & 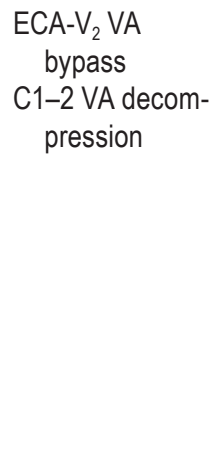 \\
\hline $\begin{array}{l}\text { Far-lateral } \\
\text { approach }\end{array}$ & $\begin{array}{l}\text { Subperiosteal dissection } \\
\text { of craniovertebral } \\
\text { junction muscles } \\
\text { down to C1-2 laminae } \\
\text { Exposure of VA from } \\
\text { medial to lateral \& } \\
\text { distal to proximal }\end{array}$ & $\begin{array}{l}\text { Compatible w/ (three-quarter) } \\
\text { prone position } \\
\text { Efficient for exposing suboc- } \\
\text { cipital triangle \& } V_{3} V A\end{array}$ & $\begin{array}{l}\text { Risk of VA injury dur- } \\
\text { ing subperiosteal } \\
\text { muscle dissection } \\
\text { Proximal control } \\
\text { achieved late in } \\
\text { the procedure }\end{array}$ & $\begin{array}{l}\text { Dissecting } V_{3} \text { aneurysm } \\
\text { Posterior fossa pathologies (e.g., } \\
\text { tumors, aneurysms, vascular } \\
\text { insufficiency) requiring bypass } \\
\text { Supratentorial pathologies requir- } \\
\text { ing bypass }\end{array}$ & $\begin{array}{l}\mathrm{V}_{2} / \mathrm{V}_{3}-\mathrm{RAG}-\mathrm{V}_{4} \\
\text { bypass } \\
\mathrm{V}_{2} / \mathrm{V}_{3}-\mathrm{RAG}-\mathrm{AICA} \\
\text { bypass } \\
\mathrm{V}_{2} / \mathrm{V}_{3}-\mathrm{MCA} \\
\text { bypass }\end{array}$ \\
\hline $\begin{array}{l}\text { Subatlantic } \\
\quad \text { triangle } \\
\text { approach }\end{array}$ & $\begin{array}{l}\text { Detachment of SCM and } \\
\text { splenius capitis } \\
\text { Removal the fat pad } \\
\text { lateral to longissimus } \\
\text { capitis to expose the } \\
\text { subatlantic triangle }\end{array}$ & $\begin{array}{l}\text { Compatible w/ (three-quarter) } \\
\text { prone \& lateral positions } \\
\text { The "natural" tissue planes } \\
\text { are used to expose the VA } \\
\text { Minimal sharp dissection re- } \\
\text { duces the risk of VA injury } \\
\text { Proximal control gained early } \\
\text { during the procedure }\end{array}$ & $\begin{array}{l}\text { Not compatible } \\
\text { w/ anterior ap- } \\
\text { proaches } \\
\text { Risk of wound dehis- } \\
\text { cence because of } \\
\text { initial layer-by- } \\
\text { layer dissection }\end{array}$ & $\begin{array}{l}\text { Dissecting } \mathrm{V}_{3} \text { aneurysm } \\
\text { Traumatic } \mathrm{C} 1-2 \text { VA injuries } \\
\text { Craniocervical junction tumors } \\
\text { encasing } \mathrm{V}_{3} \\
\text { Posterior fossa pathologies (e.g., } \\
\text { tumors, aneurysms, vascular } \\
\text { insufficiency) requiring bypass } \\
\text { Congenital or degenerative } \\
\text { C1-2 pathologies requiring } \\
\text { decompression }\end{array}$ & $\begin{array}{l}\mathrm{V}_{2}-\mathrm{RAG}-\mathrm{V}_{4} \\
\text { bypass } \\
\mathrm{C} 1-2 \mathrm{VA} \text { injury } \\
\text { repair } \\
\mathrm{V}_{2}-\mathrm{RAG}-\mathrm{PICA} \\
\text { bypass } \\
\mathrm{V}_{2}-\mathrm{RAG}-\mathrm{PICA} \\
\text { bypass } \\
\mathrm{C} 1-2 \text { VA decom- } \\
\text { pression }\end{array}$ \\
\hline
\end{tabular}

AICA = anterior inferior cerebellar artery; $\mathrm{MCA}=$ middle cerebral artery; PICA = posterior inferior cerebellar artery; RAG = radial artery graft.

${ }^{*}$ The listed scenarios and procedure examples are not inclusive of all plausible clinical scenarios in which each approach could be used.

junction musculature to localize the C-1 and C-2 transverse processes. ${ }^{22}$ The limitations of this approach are essentially similar to any other inferior extension of the far-lateral approach to expose the atlantoaxial VA, because the bulk of muscles pushed laterally would create an obstacle against easy identification of the C-1 and C-2 transverse processes. Furthermore, the technique proposed by La Rocca et al. is dependent on identification of the suboccipital triangle, which may be distorted by the pathology or scarring from previous surgery.

\section{Study Limitations}

This study lacks clinical material to support our results. Specifically, when a lesion distorts the regional anatomy, the subatlantic triangle may be less useful for early localization of the atlantoaxial VA. However, the present work lays a foundation for the clinical application of the proposed technique for early and safe exposure and control of the atlantoaxial VA through a posterior trajectory.

\section{Conclusions}

The subatlantic triangle offers a simple and straightforward gateway to expose the atlantoaxial VA without exposing the IJV or the accessory nerve. This technique could be of benefit when early control of the atlantoaxial VA is required during a posterior approach to the craniovertebral junction. It could be easily integrated into the muscular stage of the far-lateral approach. Clinical application of this technique helps in defining its role in the surgery of the craniovertebral junction.

\section{References}

1. Al-Mefty O, Borba LA, Aoki N, Angtuaco E, Pait TG: The transcondylar approach to extradural nonneoplastic lesions of the craniovertebral junction. J Neurosurg 84:1-6, 1996

2. Avellanosa AM, Glasauer FE, Oh YS: Traumatic vertebral arteriovenous fistula associated with cervical spine fracture. J Trauma 17:885-888, 1977

3. Bertalanffy H, Seeger W: The dorsolateral, suboccipital, transcondylar approach to the lower clivus and anterior portion of the craniocervical junction. Neurosurgery 29:815821,1991

4. Bruneau M, Cornelius JF, George B: Anterolateral approach to the V2 segment of the vertebral artery. Neurosurgery 57 (4 Suppl):262-267, 2005

5. Bruneau M, Cornelius JF, George B: Antero-lateral approach to the V3 segment of the vertebral artery. Neurosurgery 58:ONS29-ONS35, 2006 
6. Chen YA, Qu RB, Bian YS, Zhu W, Zhang KP, Pang Q: Stent placement to treat ruptured vertebral dissecting aneurysms. Interv Neuroradiol 19:479-482, 2013

7. Chou SN, French LA: Arteriovenous fistula of vertebral vessels in the neck. J Neurosurg 22:77-80, 1965

8. Ciappetta P, D'Urso PI, Colamaria A: Giant craniovertebral junction hemorrhagic schwannoma: case report. Neurosurgery 62:E1166, 2008

9. Clark K, Perry MO: Carotid vertebral anastomosis: an alternate technic for repair of the subclavian steal syndrome. Ann Surg 163:414-416, 1966

10. Corkill G, French BN, Michas C, Cobb CA III, Mims TJ: External carotid-vertebral artery anastomosis for vertebrobasilar insufficiency. Surg Neurol 7:109-115, 1977

11. Della Pepa GM, Montano N, Lucantoni C, Alexandre AM, Papacci F, Meglio M: Craniotomy repair with the retrosigmoid approach: the impact on quality of life of meticulous reconstruction of anatomical layers. Acta Neurochir (Wien) 153:2255-2258, 2011

12. Elkin DC, Harris MH: Arteriovenous aneurysm of the vertebral vessels: report of ten cases. Ann Surg 124:934-949, 1946

13. Fine AD, Cardoso A, Rhoton AL Jr: Microsurgical anatomy of the extracranial-extradural origin of the posterior inferior cerebellar artery. J Neurosurg 91:645-652, 1999

14. George B, Laurian C: Surgical approach to the whole length of the vertebral artery with special reference to the third portion. Acta Neurochir (Wien) 51:259-272, 1980

15. George B, Laurian C: Surgical possibilities in the third portion of the vertebral artery (above $\mathrm{C} 2$ ). Anatomical study and report of a case of anastomosis between subclavian artery and vertebral artery at C1-C2 level. Acta Neurochir Suppl (Wien) 28:263-269, 1979

16. Gortvai P: Insufficiency of vertebral artery treated by decompression of its cervical part. Br Med J 2:233-234, 1964

17. Hakuba A, Komiyama M, Tsujimoto T, Ahn MS, Nishimura $\mathrm{S}$, Ohta T, et al: Transuncodiscal approach to dumbbell tumors of the cervical spinal canal. J Neurosurg 61:1100 1106,1984

18. Hanakita J, Miyake H, Nagayasu S, Nishi S, Suzuki T: Angiographic examination and surgical treatment of bow hunter's stroke. Neurosurgery 23:228-232, 1988

19. Hardin CA, Poser CM: Rotational obstruction of the vertebral artery due to redundancy and extraluminal cervical fascial bands. Ann Surg 158:133-137, 1963

20. Henry AK: Extensile Exposure. Edinburgh: Churchill Livingstone, 1966

21. Kornmesser TW, Bergan JJ: Anatomic control of vertebral arteriovenous fistulas. Surgery 75:80-86, 1974

22. La Rocca G, Altieri R, Ricciardi L, Olivi A, Della Pepa GM: Anatomical study of occipital triangles: the 'inferior' suboccipital triangle, a useful vertebral artery landmark for safe postero-lateral skull base surgery. Acta Neurochir (Wien) 159:1887-1891, 2017

23. Laus M, Alfonso C, Ferrari D, Gamberini G, Malaguti MC, Zappoli FA, et al: Lateral retrovascular approach to the upper cervical spine. Chir Organi Mov 80:65-75, 1995

24. Lim SH, Shin HS, Lee SH, Koh JS: Endovascular treatment of vertebral artery dissecting aneurysms that cause subarachnoid hemorrhage: consideration of therapeutic approaches relevant to the angioarchitecture. J Korean Neurosurg Soc 58:175-183, 2015

25. Matsuyama T, Morimoto T, Sakaki T: Comparison of C1-2 posterior fusion and decompression of the vertebral artery in the treatment of bow hunter's stroke. J Neurosurg 86:619623,1997

26. Miller JD, al-Mefty O, Middleton TH III: Synovial cyst at the craniovertebral junction. Surg Neurol 31:239-242, 1989

27. Miyamoto S, Kikuchi H, Nagata I, Akiyama Y, Itoh K, Ya- magiwa O, et al: Saphenous vein graft to the distal vertebral artery between C-1 and C-2 using a lateral-anterior approach. Technical note. J Neurosurg 77:812-815, 1992

28. Pásztor E: Decompression of vertebral artery in cases of cervical spondylosis. Surg Neurol 9:371-377, 1978

29. Redtenbacher M, Chouéki A, Firbas W: Surgical anatomy of the upper vertebral artery. Acta Neurochir (Wien) 92:37-38, 1988

30. Rhoton AL Jr: The far-lateral approach and its transcondylar, supracondylar, and paracondylar extensions. Neurosurgery 47 (3 Suppl):S195-S209, 2000

31. Sanson LJ: Des hemorrhagies traumatiques. Paris: Baillière, 1836

32. Shumacker HB Jr, Campbell RL, Heimburger RF: Operative treatment of vertebral arteriovenous fistulas. J Trauma 6:3-19, 1966

33. Su W, Gou S, Ni S, Li G, Liu Y, Zhu S, et al: Management of ruptured and unruptured intracranial vertebral artery dissecting aneurysms. J Clin Neurosci 18:1639-1644, 2011

34. Suma T, Shibuya T, Kutsuna N, Takada Y, Matsuzaki T, Nakamura S, et al: Endovascular treatment for ruptured vertebral artery dissecting aneurysms at the acute stage. Acta Neurochir Suppl 118:273-276, 2013

35. Tabatabai SA, Zadeh MZ, Tayebi Meybodi A, Hashemi M: Extracranial aneurysm of the posterior inferior cerebellar artery with an aberrant origination: case report. Neurosurgery 61:E1097-E1098, 2007

36. Tamano Y, Kobayashi T, Hagiwara S, Tanaka N, Ide M, Kawamura H: Aneurysm of the distal posterior inferior cerebellar artery originating from the extracranial and extradural vertebral artery. Neurol Med Chir (Tokyo) 43:301-303, 2003

37. Tayebi Meybodi A, Benet A, Lawton MT: The V3 segment of the vertebral artery as a robust donor for intracranial-tointracranial interpositional bypasses: technique and application in 5 patients. J Neurosurg [epub ahead of print October 6, 2017; DOI: 10.3171/2017.4.JNS163195]

38. Tayebi Meybodi A, Lawton MT, Benet A: Dual origin of extradural posterior inferior cerebellar artery from vertebral and occipital arteries: anatomic case report. Oper Neurosurg (Hagerstown) 11:564-568, 2015

39. Tayebi Meybodi A, Lawton MT, Mokhtari P, Kola O, ElSayed IH, Benet A: Exposure of the external carotid artery through the posterior triangle of the neck: a novel approach to facilitate bypass procedures to the posterior cerebral circulation. Oper Neurosurg (Hagerstown) 13:374-381, 2017

40. Tayebi Meybodi A, Rincon-Torroella J, El-Sayed IH, Lawton MT, Benet A: Early localization of the third segment of the vertebral artery: the atlanto-mastoid line. Oper Neurosurg (Hagerstown) 12:350-359, 2015

41. Tubbs RS, Shoja MM, Acakpo-Satchivi L, Wellons JC III, Blount JP, Oakes WJ, et al: Exposure of the V1-V3 segments of the vertebral artery via the posterior cervical triangle: a cadaveric feasibility study. J Neurosurg Spine 5:320-323, 2006

42. Türe U, Ozek M, Pamir MN: Lateral approach for resection of the $\mathrm{C} 3$ corpus: technical case report. Neurosurgery 52:977-981, 2003

43. Verbiest H: Extracranial and cervical arteriovenous aneurysms of the carotid and vertebral arteries. Report of a series of 12 personal cases. Johns Hopkins Med J 122:350-357, 1968

44. Wang J, Ou SW, Wang YJ, Wu AH, Wu PF, Wang YB: Microsurgical management of dumbbell $\mathrm{C} 1$ and $\mathrm{C} 2$ schwannomas via the far lateral approach. J Clin Neurosci 18:241246, 2011

45. Wanibuchi M, Fukushima T, Zenga F, Friedman AH: Simple identification of the third segment of the extracranial vertebral artery by extreme lateral inferior transcondylar- 
transtubercular exposure (ELITE). Acta Neurochir (Wien) 151:1499-1503, 2009

46. Yang T, Tariq F, Duong HT, Sekhar LN: Bypass using V2-V3 segment of the vertebral artery as donor or recipient: technical nuances and results. World Neurosurg 82:1164-1170, 2014

\section{Disclosures}

The authors report no conflict of interest concerning the materials or methods used in this study or the findings specified in this paper.

\section{Author Contributions}

Conception and design: Lawton, Tayebi Meybodi, Preul. Acquisition of data: Tayebi Meybodi, Gandhi. Analysis and interpretation of data: Tayebi Meybodi, Gandhi. Drafting the article: Tayebi Meybodi, Gandhi. Critically revising the article: all authors. Reviewed submitted version of manuscript: all authors. Approved the final version of the manuscript on behalf of all authors: Lawton. Statistical analysis: Tayebi Meybodi, Gandhi. Study supervision: Lawton, Preul.

\section{Correspondence}

Michael T. Lawton: Barrow Neurological Institute, Phoenix, AZ. michael.lawton@barrowbrainandspine.com. 